\title{
O fotolivro no ambiente tecnoimagético: considerações sobre a dimensão crítica da fotografia a partir de The Americans, de Robert Frank
}

\author{
Wagner Souza e Silva \\ Universidade de São Paulo, Escola de Comunicações e Artes, Departamento de Jornalismo e Editoração, \\ São Paulo, SP, Brasil \\ ORCID: https://orcid.org/0000-0003-3839-2305
}

Bruna Sanjar Mazzilli

Universidade de São Paulo, Escola de Comunicações e Artes, Departamento de Jornalismo e Editoração, São Paulo, SP, Brasil

\begin{abstract}
Resumo
Com a crescente retomada dos fotolivros no campo editorial, este artigo tem por objetivo discutir a relevância desses objetos para a circulação da fotografia, sobretudo num momento em que o cenário comunicacional se baseia numa ambiência tecnoimagética de onipresença da imagem digital e da tela como suporte. Tem-se, como estratégia de análise, a abordagem do percurso editorial do livro The Americans, de Robert Frank, desde sua primeira edição, em 1958, até a versão mais recente, de 2008. Sugere-se que a insistência dessa obra como uma importante referência evidencia que o livro, além de ser um relevante espaço para a circulação e divulgação, é decisivo para a expansão do potencial crítico da fotografia.
\end{abstract}

\section{Palavras-chave}

Fotografia. Robert Frank. Fotolivro. Tecnoimagem.

\section{Introdução}

Ainda que seja possível constatar o amplo espaço para a circulação de imagens digitais, o livro impresso continua sendo um importante suporte para a fotografia. Há, em curso, um significativo incremento da produção editorial nesse nicho e, tal como constataram Parr e Badger (2006), nunca se produziram tantos fotolivros como atualmente. 
No ensaio O que é a história dos livros?, publicado pela primeira vez em 1982, Robert Darnton (1993) defende o livro como um meio de comunicação, colocando-o dentro de um circuito integrado que conecta seus agentes (autores, editores, impressores, distribuidores, vendedores etc.) à sua conjuntura (econômica, social, política, intelectual). De certa forma, o autor sustenta a concepção de que estudar livros - e sua história - é estudar como as ideias são transmitidas e como esse meio de transmissão afeta o pensamento e o comportamento humanos (e vice-versa) (DARNTON, 1993).

Entende-se que tais apontamentos podem ser também estendidos aos fotolivros, que por muito tempo foram os meios mais bem-sucedidos para divulgar o trabalho autoral de vários fotógrafos. E o resgate contemporâneo dessa forma de divulgar projetos fotográficos, fazendo frente às telas eletrônicas, aponta para um campo de reflexão capaz de evidenciar aspectos da cena comunicacional por meio de imagens, e, ao mesmo tempo, atualizar o estatuto do livro como meio de comunicação na cena digital.

A fim de evidenciar essa dimensão comunicacional do fotolivro, este artigo tem como estratégia voltar os olhos para o percurso editorial da obra The Americans [Os americanos], do fotógrafo suíço Robert Frank. Publicado pela primeira vez em 1958, na França, o livro foi um marco para a história dos fotolivros e da fotografia e, ainda hoje, é tido como uma importante referência entre críticos, curadores, fotógrafos e editores. A relevância desse trabalho também se traduz na sua expansão em forma de exposições, já realizadas em grandes museus e espaços destinados à fotografia ao redor do mundo (foi, inclusive, a exposição escolhida para inaugurar a sede do Instituto Moreira Salles na cidade de São Paulo, em setembro de 2017) ${ }^{1}$.

The Americans é uma obra que, além de representar toda a sinergia envolvida na produção de um fotolivro, traz à tona o potencial crítico que a fotografia é capaz de agenciar, potencial este que está atualmente em constante confronto com uma ambiência cada vez mais alicerçada por uma abundância imagética advinda da tela onipresente.

\footnotetext{
${ }^{1}$ Robert Frank: Os americanos + os livros e os filmes, 20 set. 2017-30 dez. 2017. A exposição, concebida em parceria com o editor Gerhard Steidl, trouxe as 83 fotografias (em cópias vintage) presentes em The Americans, além da reprodução de alguns de seus contatos e exemplares de diferentes edições do livro. Também estavam presentes outros livros de Frank, bem como suas produções em filme e vídeo.
} 


\section{Um percurso editorial}

The Americans reúne 83 fotografias produzidas entre 1955 e 1956, durante uma jornada que Robert Frank fez pelos Estados Unidos com uma bolsa da fundação Guggenheim. Em um carro usado, Frank rodou praticamente todos os Estados do país para registrar a vida dos norte-americanos no pós-guerra, captando-os nas mais diversas circunstâncias ${ }^{2}$. No total, foram mais de 27 mil imagens clicadas ao longo dos nove meses de viagem, das quais Frank selecionou as 83 que compõem o livro, publicado pela primeira vez em 1958 por Robert Delpire, na França.

No projeto, Frank estabeleceu uma linguagem autoral, expressiva e despojada de tecnicismos fotográficos. Ou seja, nem todas as imagens são tecnicamente bem resolvidas; algumas são bastante granuladas, outras têm um enquadramento incomum, outras ainda estão estouradas ou ligeiramente desfocadas. Isso não quer dizer que não haja complexidade gráfica no material, como aponta Sarah Greenough (2017) ao falar das várias nuances tonais e luminosas captadas por Frank. Mas, no conjunto, o que se nota é uma postura mais desprendida na tomada das imagens, especialmente quando consideramos os projetos de fotografia documental do período, em sua maioria ainda muito guiados por um alto rigor técnico. Da mesma maneira, a sequência fotográfica idealizada por Frank reforça a pessoalidade do projeto, pois demarca um posicionamento crítico ao intercalar os vários conflitos e paradoxos constitutivos da nação norte-americana (liberdade e racismo, exclusão/pobreza e glamour/riqueza, ócio e trabalho, vida e morte etc.).

Se a proposta de The Americans foi de fato inovadora para o período, nem por isso a primeira edição do livro atendeu exatamente ao que seu autor esperava. Acreditando, assim como Walker Evans, que fotografias "falam por elas mesmas" (STEIDL, 2017a), sem necessidade de textos que as expliquem, Frank pretendia fazer um livro simples, só com as imagens e uma das fotos na capa. Mas como essa era uma concepção muito radical para o período, o editor da obra, Robert Delpire, não quis correr grandes riscos. Guiado por uma

\footnotetext{
2 A ideia de fazer uma expedição fotográfica pelos Estados Unidos não era exatamente algo novo. Walker Evans, outro importante fotógrafo do período, já havia feito algo semelhante duas décadas antes, em 1938, com o livro American Photographs (Fotografias americanas). Como sugere Badger (2015), Evans foi capaz de demonstrar com propriedade que a fotografia poderia ser muito mais do que um simples método de documentação; ela poderia, em sua essência, ser uma "[...] arte literária, na qual fotos ordenadas em uma sequência específica podiam dizer algo mais que a mera soma de suas partes isoladas." (BADGER, 2015, p. 135). Dando um passo além dos fotoensaios existentes no período, Evans não só pensou na relação entre as imagens, mas também introduziu metáforas e símbolos em sua narrativa, tornando-a mais profunda e complexa. A iniciativa certamente abriu espaço para que outros fotógrafos investissem e desenvolvessem uma postura mais discursiva. Frank foi um deles, ainda mais tendo Evans como amigo e mentor em seu projeto ambicioso (IMS, 2017).
} 
forte veia documental e antropológica, decidiu publicá-la como parte de uma série que ele planejava chamar de Encyclopédie essentielle (Enciclopédia essencial). Cada uma das 83 imagens - dispostas individualmente nas páginas ímpares - era acompanhada de um pequeno texto na página par assinado por algum grande nome da literatura, como Simone de Beauvoir, Erskine Caldwell, William Faulkner e John Steinbeck (PARR; BADGER, 2004). Na capa, além do título em francês (Les Américains) e do crédito a Robert Frank, figurava um desenho de Nova York feito por Saul Steinberg, percorrendo também a quarta capa. Assim, apesar de as 83 imagens seguirem a sequência originalmente concebida por Frank, sua autonomia semântica era colocada em xeque pela presença de tantos textos verbais que sugeriam uma interpretação já determinada das fotografias.

Figura 1 - Capa, contracapa e exemplo de dupla da primeira edição de The Americans, publicada em 1958 por Robert Delpire, na França
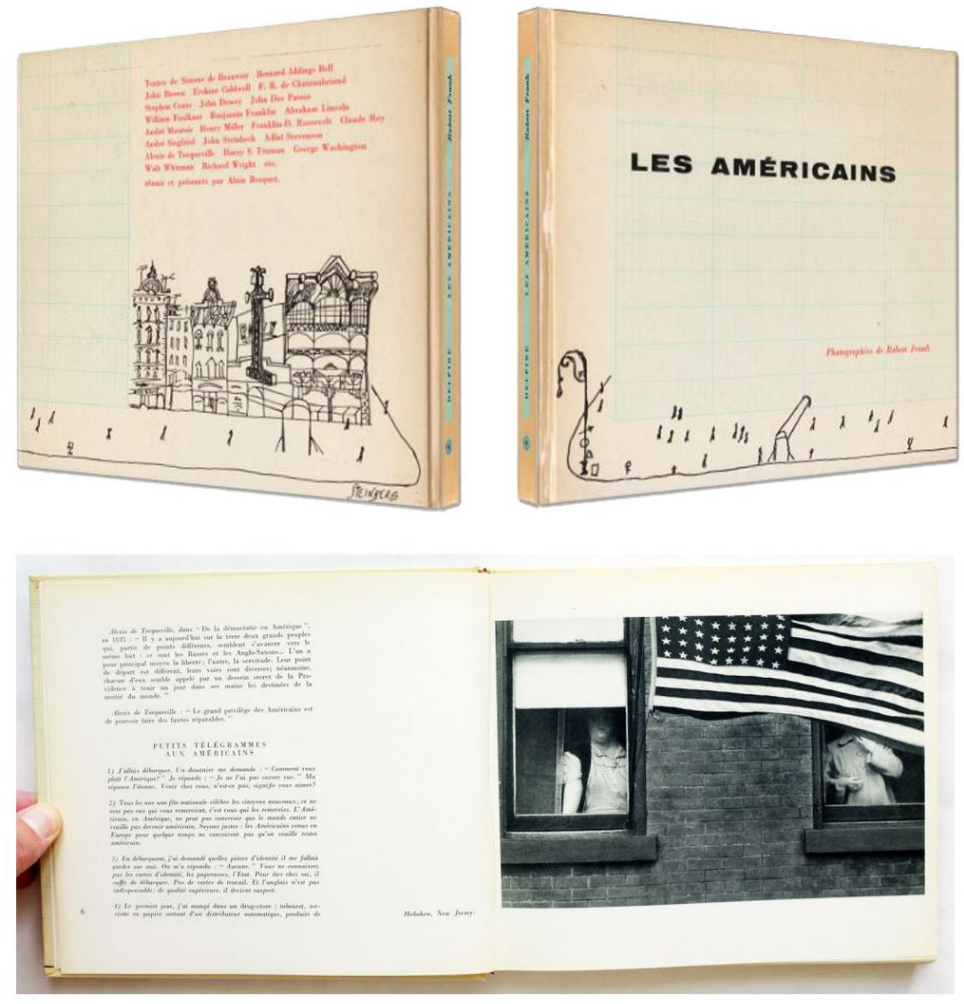

Fonte: Chladek (2019).

Essa grave incongruência foi parcialmente resolvida com a primeira edição norteamericana da obra, publicada em 1959 pela Grove Press. Com a sequência original mantida, os textos das páginas pares saíram para dar lugar a breves legendas sobre as fotos. Ainda 
sob certa preocupação dos editores (STEIDL, 2017b), um pequeno texto introdutório foi incluído, mas dessa vez sem fazer uma leitura histórica ou sociológica das imagens. A pedido do próprio Frank, quem assina o texto é o escritor beat Jack Kerouac, com quem havia se encontrado pela primeira vez em 1957, após o lançamento de seu livro On the Road (Na estrada) - outra obra que marcou o período pelo estilo desprendido e contínuo de sua narrativa, um longo fluxo de consciência que coloca a estrada como uma metáfora da busca pela experiência autêntica. Daí, também, a identificação entre os dois autores: a exemplo de Kerouac, Frank sai em uma jornada de descobertas pelo território americano e constrói seu próprio fluxo de consciência fotográfico, intuitivo e altamente pessoal. A introdução a The Americans procurará seguir essa mesma linha, usando um tom mais espontâneo e despretensioso para transmitir o espírito geral do projeto. No final do texto, Kerouac (2017) descreve Frank como um fotógrafo "[...] suíço, discreto, simpático, [...] [que] sugou um poema triste dos Estados Unidos e o passou para seu filme, perfilando-se entre os poetas trágicos do mundo." (KEROUAC, 2017, p. 12). Completa: "Se alguém não gostar dessas fotos é porque não gosta de poesia, tá bem?" (KEROUAC, 2017, p. 12).

Essa nova edição também modificou o tamanho do livro e o layout da capa, em consonância com as primeiras ideias de Frank: as dimensões foram reduzidas de 19,5 x $22,5 \mathrm{~cm}$ para $18,5 \times 21 \mathrm{~cm}$ e uma das fotografias do miolo foi colocada na capa, acompanhada do título em inglês e dos nomes de Kerouac e Frank. A imagem escolhida foi Bonde, Nova Orleans, que estampou a maior parte das edições seguintes e hoje é, provavelmente, a mais conhecida de todo o conjunto. 
Figura 2 - Capa, contracapa e exemplo de dupla da segunda edição de The Americans, publicada em 1959 pela Grove Press, nos EUA

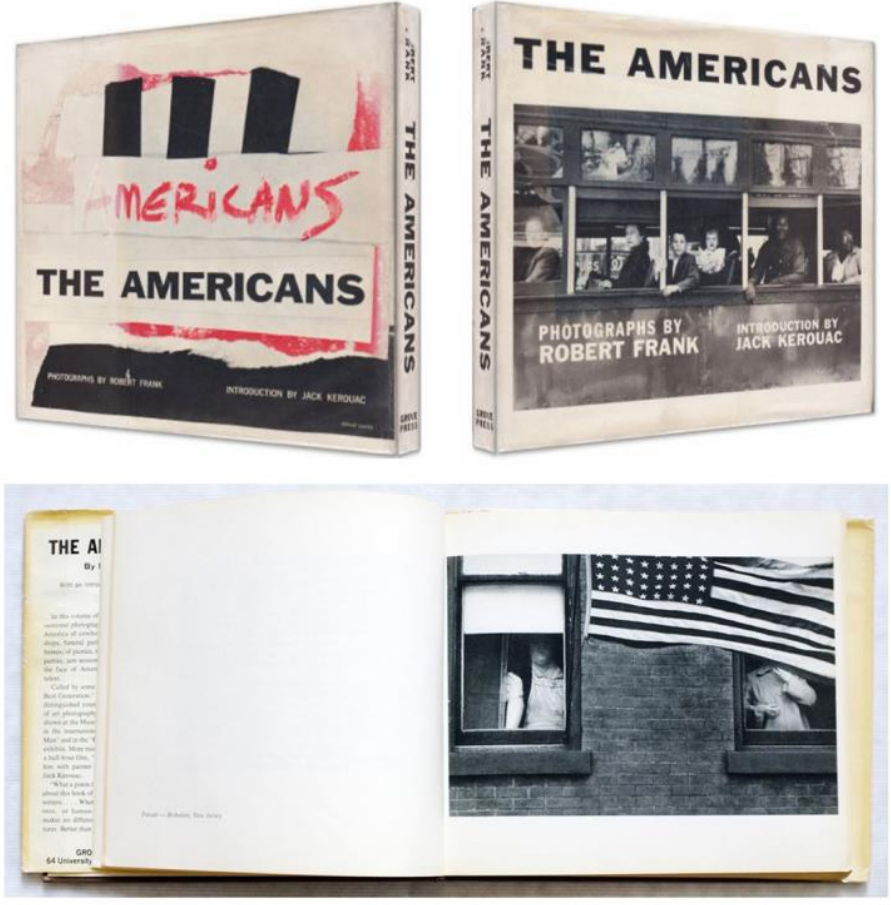

Fonte: Chladek (2019).

A edição da Grove Press reparou muitas falhas da edição francesa, mas foi preciso certo tempo para que se consolidasse como uma referência no campo. A proposta não foi muito bem recebida em território americano durante os primeiros anos de sua publicação, rodeada de críticas negativas que apontavam o livro como uma "[...] condenação mordaz do país e seus habitantes [...]" (GREENOUGH, 2017, p. 30, tradução nossa). Nesse cenário, com as vendas escassas, a editora decidiu declarar o livro esgotado em dezembro de 1960, tendo vendido pouco mais de 1.100 cópias. Amigos e colegas de Frank logo partiram em sua defesa, dentre os quais o também fotógrafo Edward Steichen, que na época era curador do Museu de Arte Moderna de Nova York (MoMA). Aproveitando o espaço do museu, Steichen montou uma exposição de quase 80 fotografias do livro, que permaneceu em cartaz de janeiro a abril de 1962. Apesar de a ordem original das imagens não ter sido respeitada, a qualidade das ampliações superava em muito a das pequenas cópias que Frank havia feito originalmente; as fotos eram mostradas em grandes dimensões e com todas as suas nuances tonais. Uma versão reduzida da exposição viajou por outros Estados dos EUA até 1964, levando as fotos de Frank a públicos mais distantes (GREENOUGH, 2017). 
Outra iniciativa que contribuiu para a circulação do trabalho de Frank foi a exposição itinerante concebida em 1965 pelo também fotógrafo e curador Nathan Lyons, percorrendo os Estados Unidos e o Japão até 1980. Nesse meio tempo, à medida que muitas das questões abordadas em The Americans eram incorporadas pelo consciente coletivo (racismo, alienação, insatisfação com o sistema político etc.), o livro começou a ser valorizado por sua condição antecipadora e revolucionária (GREENOUGH, 2017). No fim dos anos 1960, The Americans era já um livro aclamado praticamente em todo o mundo, mas difícil de ser encontrado.

Assim, em 1968, uma nova edição foi publicada pela Aperture em parceria com o MoMA, acompanhada de uma exposição no Museu de Arte da Filadélfia em 1969. A sequência e a introdução foram mantidas, com pequenas mudanças de layout, enquadramento das imagens e tamanho. Comparada com as precedentes, porém, essa edição foi extremamente malfeita: as imagens dançavam nas páginas, por vezes sangrando à direita ou à esquerda e sem seguir um padrão para as margens superiores e inferiores; a impressão também havia deixado as fotos muito mais pálidas do que as reproduções de 1958/59. Diante disso, o livro foi republicado no ano seguinte, em parceria com a Grossmann Publishers. 0 posicionamento das imagens foi corrigido, mas a qualidade da impressão ainda deixava muito a desejar. As fotos acabaram saindo contrastadas demais, perdendo muitos dos detalhes em altas luzes e sombras que as primeiras edições haviam conseguido reproduzir bem. A ausência desses detalhes sugeria, então, um Robert Frank bastante mais desprendido e casual, que desdenhava da técnica em função dos motivos que queria retratar.

Embora um pouco exagerada, essa foi a concepção do livro que acabou predominando naquele momento, pois foi também essa edição de 1969 a que se consagrou como uma bíblia para uma importante geração de fotógrafos nos anos 1970. A Aperture ainda fez uma nova tentativa quase uma década depois, em 1978, mas agora suas escolhas editoriais apontavam para um caminho praticamente oposto: as tonalidades estavam mais claras e bem menos evocativas, além de os enquadramentos serem maiores do que os originalmente pensados por Frank em 1958 e 1959. Parecia que as imagens falavam menos dos americanos e mais da relação que as pessoas estabeleciam com seus ambientes. Ao mesmo tempo, essa estética acompanhava as tendências da fotografia de rua que despontavam naquele momento, inspiradas pelo próprio trabalho de Frank nas últimas décadas (GREENOUGH, 2017). 
As edições seguintes - Delpire/Pantheon, 1985/86; Scalo/National Gallery of Art, 1993; Steidl/National Gallery of Art, 2008 - continuaram com as variações gráficas e de layout, por vezes alterando a capa, a disposição das legendas e o enquadramento das imagens. Nesse sentido, a edição de 2008, da Steidl, é uma que merece destaque, porque encerra esse ciclo de mudanças e estabelece uma edição do livro que é considerada definitiva, cujas diretrizes devem ser seguidas por quaisquer outras editoras interessadas em publicar a obra a partir de então.

Comparada às demais, essa é provavelmente a edição mais simples e a mais bem alinhada com as ideias de Frank, considerando a liberdade que Gerhard Steidl, o responsável pela editora, lhe dava no processo de confecção de seus livros. A relação entre ambos não começa propriamente em 2008, mas no fim dos anos 1980, quando Steidl ainda trabalhava como impressor para a editora suíça Scalo e estava ajudando a produzir a edição de 1993 do livro de Frank. Em 2004, a Scalo declarou falência e Steidl aproveitou para adquirir os direitos de publicação de The Americans, trazendo Frank para sua própria editora. Com a parceria renovada, vários de seus livros publicados por outras editoras e já fora de circulação, bem como livros nunca antes publicados, ganharam novas edições, todas supervisionadas por Steidl e conforme as decisões de Frank. 
Figura 3 - A edição 'definitiva' de The Americans, publicada por Gerhard Steidl em 2008. Acima: capa e detalhe da impressão; abaixo: exemplo de dupla

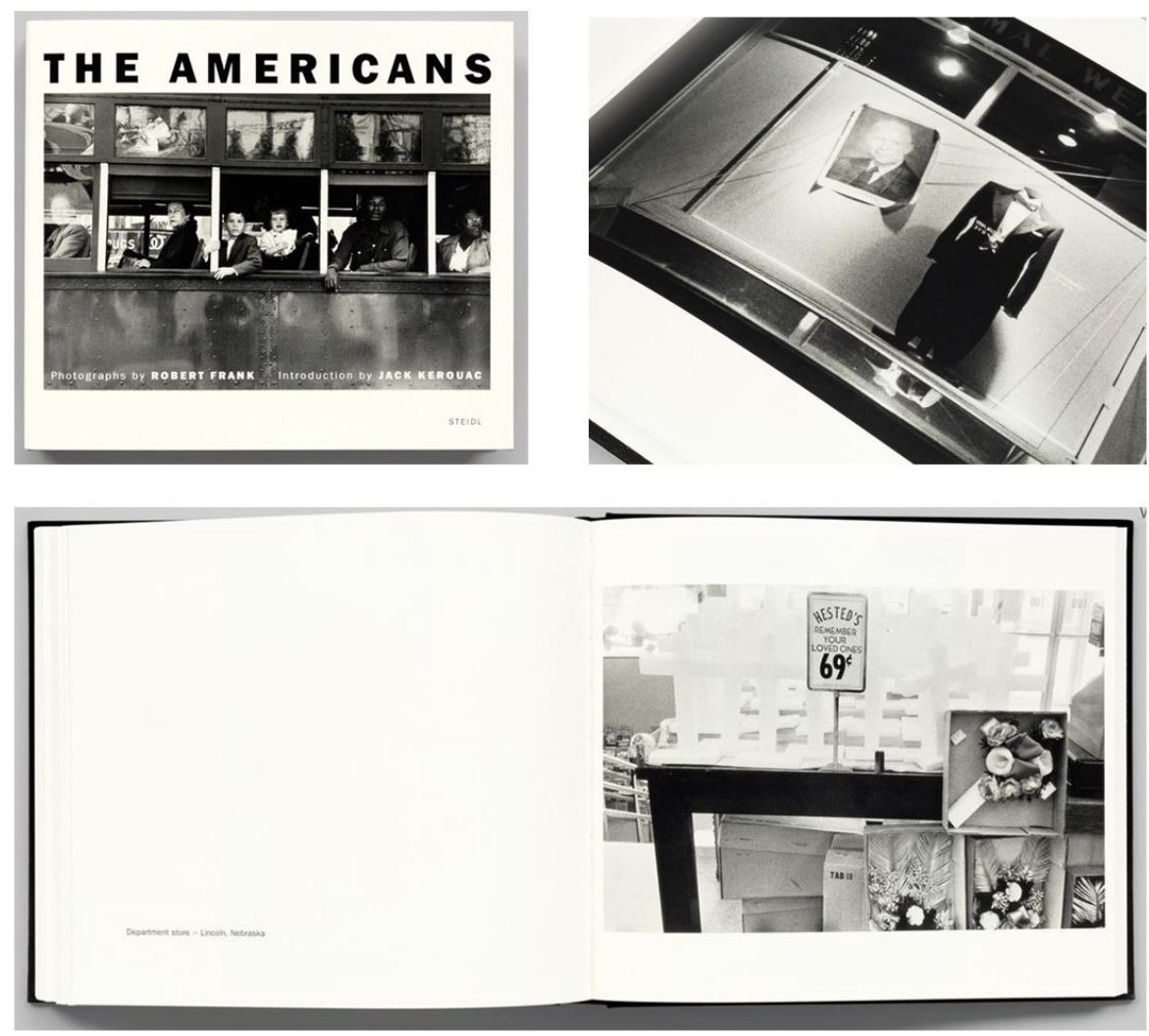

Fonte: Steidl (2019).

No caso de The Americans, pensando em fazer uma edição final do livro no ano de seu quinquagésimo aniversário, Steidl perguntou a Frank como ele gostaria que fosse essa última edição, ao que obteve como resposta: "Eu sou um fotógrafo simples, então quero fazer um livro simples." (STEIDL, 2017a, doc. não paginado). A começar pelo tamanho, ainda menor que o das edições da Delpire e da Grove Press: 20,9 x 18,4 cm. Quanto aos materiais e acabamentos, concluíram que precisavam de apenas três elementos: um bom papel para o miolo, as guardas e a sobrecapa, que seria o mesmo nos três casos; um papel-cartão para a encadernação; e um tecido preto para revestir o papel-cartão. Além, é claro, de uma boa impressão, fundamental para trazer todas as nuances e detalhes das fotografias. A propósito, Steidl decidiu partir não dos negativos de Frank, mas das cópias vintage que o fotógrafo guardara consigo para imprimir as novas reproduções.

Outro ponto importante nesse processo foi a decisão de manter ou não as legendas e o texto introdutório de Kerouac. Steidl sabia que Frank nunca tivera a intenção de publicar 
seu livro com qualquer tipo de texto, então também lhe ofereceu a possibilidade de removêlo e ficar apenas com as imagens, conforme a proposta original. A princípio, Frank abraçou a ideia, insistindo que fotografias não precisam de explicação ou interpretação; pouco depois, porém, voltou atrás, declarando que ninguém realmente entenderia por que, depois de 50 anos, os textos e as legendas haviam de repente sido retirados. No mais, como teria dito a Steidl, "O texto é bom, e as legendas oferecem aos leitores alguma orientação sobre em que lugares dos Estados Unidos cada foto foi feita." (STEIDL, 2017a, doc. não paginado). Levando isso em conta, texto e legendas foram, enfim, mantidos.

\section{0 fotolivro no ambiente tecnoimagético}

Essa relevância atribuída a The Americans, que se estende até os dias atuais, é ressonante ao crescente espaço que os fotolivros vêm obtendo no ambiente imagético contemporâneo. Se tomarmos de empréstimo de Vilém Flusser $(2002,2008)$ o seu conceito de "tecnoimagem" (ou imagem técnica) para definirmos a fotografia, há de se considerar importantes pontos de apoio para sustentar a análise dessa retomada dos fotolivros.

Segundo Flusser, tecnoimagens não devem ser equiparadas às imagens tradicionais porque são produzidas por aparelhos, sendo a câmera fotográfica o aparelho pioneiro: ao realçar o caráter "automático" na feitura da tecnoimagem, Flusser $(2002,2008)$ chama atenção para a constituição de sua estrutura, buscando evidenciar sua formação pela junção de pontos infinitesimais (FLUSSER, 2002, 2008). Nesse sentido, tanto as fotografias constituídas a partir de sais de prata (filme, papel) como aquelas formadas por cargas elétricas (mídia digital) podem ser consideradas tecnoimagens. 0 autor ainda emoldura o universo das tecnoimagens pelo conceito de "superficialidade": "Graças a fotos, filmes, a vídeo, a jogos de computador [...] tendemos atualmente a desprezar 'explicação profunda' e a preferir a 'superficialidade empolgante';" (FLUSSER, 2008, p. 45).

A superficialidade permite, portanto, aproximações entre o fotolivro e a tela, configurando-os como elementos constituintes de um mesmo ambiente tecnoimagético. Assim, o entendimento da fotografia como tecnoimagem pode deslocar a análise mais para a diferenciação material dos suportes, isto é, aquela existente entre livro e tela, garantindo um ponto de apoio para sustentar a hipótese de que a ascensão do nicho editorial dos fotolivros seria a contraposição destes, como objetos impressos, à efemeridade da imagem eletrônica das telas. 
Quando Flusser (2008) estabelece os parâmetros de definição da tecnoimagem, ele o faz a partir de uma proposta fenomenológica da história do homem, que, segundo o filósofo, se deu a partir de um crescente afastamento em relação ao mundo concreto que o cerca. A tecnoimagem seria o quarto estágio, após três etapas anteriores: na primeira, o homem age sobre a natureza e toma consciência do mundo tridimensional; na segunda, ele imagina antes de agir e projeta suas ações por meio de imagens bidimensionais; na terceira, por meio da escrita, o homem concebe o imaginado de forma linear, traduzindo-o para uma dimensão apenas. A tecnoimagem, o quarto estágio, ao suceder a escrita, é a própria fragmentação do texto, anulando toda e qualquer dimensão, e passa a traduzir o mundo não mais em três (objetos), duas (a imagem) ou uma (o texto) dimensões, mas por meio de uma zerodimensionalidade, o mundo em "pontos infinitesimais", como já apontado (FLUSSER, 2008, p. 15-22).

Isso posto, torna-se evidente que o fotolivro é um embate entre tais dimensões e, portanto, entre formas de se aproximar do mundo concreto, visto que o livro, objeto tridimensional, consagrou-se como meio de expressão da escrita, que é unidimensional na acepção de Flusser (2008). As fotografias, que o filósofo classifica como zerodimensionais, ao habitarem um livro, revestem-se de outras dimensões, tornando o fotolivro um objeto que nos aproxima de maneira intrigante do nosso entorno: é justamente essa constatação que propulsiona a dimensão crítica da fotografia.

No caso de The Americans, uma dessas dimensões está no próprio conteúdo imagético da obra, no modo como Frank expõe e reflete sobre um conjunto de temas que lhe são caros. Isso é especialmente notável em uma série de elementos que se repetem ao longo do livro: a bandeira norte-americana - que divide a obra em quatro seções implícitas -, os carros, a estrada, os jukeboxes, os negros, os funerais, as celebridades, os ícones religiosos... A liberdade é contrastada com o racismo, a morte com a vida, o ócio com o trabalho, a exclusão e a pobreza com a ostentação e o glamour; Frank capta várias nuances da sociedade norte-americana dos anos 1950, retomando alguns dos motivos trabalhados por Walker Evans em American Photographs ao mesmo tempo que deixa claro seu próprio posicionamento pessoal. Não se trata de uma sequência que segue parâmetros narrativos tradicionais, com um começo, um meio e um fim, mas uma sequência fragmentária, feita de partes que se contrapõem, mas coexistem - uma metáfora para a natureza do próprio país (BATE, 2013). Como afirma Bate (2013), foi por meio dessa "inovadora sintaxe fotográfica" (BATE, 2013, p. 68), capaz de romper com os parâmetros mais tradicionais da fotografia 
documental e jornalística, que The Americans passaria a ser referência para toda uma geração de fotógrafos futuros.

Mas esse caráter revolucionador de The Americans, muito sustentado pela inovação que trouxe à linguagem da fotografia, deve também ser atribuído à sua materialização na forma de livro, visto ser esse o elemento fundamental para garantir o encadeamento das contraposições que o ensaio busca estruturar. Há um equacionamento, portanto, entre o valor das fotografias e o valor do livro como suporte.

A partir de Flusser (2010), é possível notar como um livro, enquanto objeto, exige gestos que portam significados decisivos, sobretudo tendo em vista a sua localização no processo evolutivo de distanciamento entre homem e mundo, isto é, de afastamento da tridimensionalidade do concreto rumo à zerodimensionalidade da informação digital: para o filósofo, "O livro é, pode-se ver assim, um estágio intermediário que procede da floresta em direção à terra das inteligências artificiais." (FLUSSER, 2010, p. 108).

O ser humano, "[...] um habitante de espaços interiores e um experimentador de espaços exteriores [...]" (FLUSSER, 2010, p. 106), necessita, para isso, de paredes; e, para oscilar entre o dentro e o fora, necessita de portas e janelas, que, segundo o filósofo, se tornam supérfluas a partir da ascensão das telas de TV e computador. Porém, Flusser ressalta que não seria o mesmo para o caso da parede de uma biblioteca: trata-se de uma "parede de segundo grau", formada por uma sequência de livros dispostos uns ao lado dos outros. Para o autor, "Pegar e girar o livro pode servir como modelo de gesto revolucionário [uma vez que] Revolução significa com certeza olhar as paredes que nos separam [...]" (FLUSSER, 2010, p. 106). Propõe que

Nenhuma parede - exceto a parede de uma biblioteca - pode provocar uma revolução [...], [concluindo, por fim, que] Revoluções são possíveis apenas no universo histórico da parede da biblioteca, e não no das imagens técnicas. (FLUSSER, 2010, p. 110-111).

É nesse sentido que se faz notar a especificidade do fotolivro. Ele pode ser capaz de atribuir às imagens técnicas tal potencial revolucionador, distanciando-as da condição de "paredes desenvolvidas tecnicamente" (FLUSSER, 2010, p. 106); pelo contrário: permitem observar as paredes que nos separam, tal como evidencia The Americans quando se propõe ao confronto com a sociedade norte-americana, dando visibilidade a seus contrastes e conflitos. 
Flusser (2010) ainda discorre sobre o gesto do folhear como gesto labiríntico e emancipador: "Trata-se da liberdade de deixar jogar o acaso. [...] Deixamos as folhas dos livros correrem por entre os dedos, na expectativa de encontrar alguma coisa ao acaso [...]" (FLUSSER, 2010, p. 113). Nessa perspectiva flusseriana, a estrutura fragmentária da narrativa de The Americans, que já poderia ser encarada, em certa medida, como um exercício de liberdade, torna-se ainda mais expressiva, tornando possível a construção de outras conexões e sintaxes, ainda que limitadas por opções impostas pela ordem das páginas. Para Flusser (2010),

As camadas de acaso e de causa armazenadas umas sobre as outras, essa estrutura de sanduíches de explicações, fazem com que o folhear se transforme na causa, cuja consequência é um modo de leitura específico pelo qual o livro folheado pode ser decifrado. (FLUSSER, 2010, p. 113).

Vemos, assim, que a passagem dessas abordagens fenomenológicas do livro para o fotolivro permite vislumbrar uma condição única que é dada à fotografia, garantindo-lhe uma dimensão discursiva que realça sua assertividade e, consequentemente, seu potencial crítico.

\section{Considerações finais}

Se, em meio à intensa circulação imagética nas telas, paramos para contemplar, refletir e discutir sobre uma obra como The Americans, é não somente porque ela evidencia a manutenção do livro como um importante espaço para desenvolver a dimensão crítica advinda de abordagens fotográficas, mas porque também, e principalmente, continua provocando mudanças na forma de pensar e fazer imagens. Por essa perspectiva, posicionase como uma influente peça nos jogos criativos do gigante universo de imagens técnicas que Flusser (2008) denomina como superficialidade.

The Americans justifica sua importância como obra para a história da fotografia e dos fotolivros, tendo atravessado e influenciado várias gerações da mesma forma que foi influenciada por elas. Debruçar-se sobre seu percurso editorial é debruçar-se sobre as transformações na prática e no pensamento fotográficos - o que, de modo mais amplo, também não deixa de ser um estudo sobre o pensamento e o comportamento humanos, 
como Darnton (1993) sugere ao falar da história dos livros e como Flusser (2010) reforça por meio de sua análise fenomenológica.

Assim, podemos afirmar que os fotolivros, ao circularem por uma variedade de ambientes distintos e atravessarem grandes períodos de tempo, se mantêm como objetos de grande importância para o circuito comunicacional, especialmente sob uma perspectiva histórica. E não somente como um fenômeno no campo da prática fotográfica, mas também como um elemento que catalisa um embate entre formas de aproximação ao mundo, ajudando a (re)formular pensamentos e discursos sobre a realidade e as maneiras de representá-la.

\section{Referências}

BADGER, Gerry. Por que fotolivros são importantes. Zum, São Paulo, n. 8, p. 132-155, 2015.

BATE, David. The syntax of a photowork. In: BADGER, Gerry et al (org.). Imprint: visual narratives in books and beyond. Gothenburg: Negative, 2013. p. 49-75.

CHLADEK, Josef. Robert Frank - Les Américains. In: CHLADEK, Josef. Josef Chladek: on photobooks and books. [S. l.], 2019.

DARNTON, Robert. 0 que é a história dos livros? In: DARNTON, Robert. 0 beijo de Lamourette. São Paulo: Companhia das Letras, 1993. p. 109-131.

IMS. Sobre Robert Frank: os americanos + os livros e os filmes. São Paulo, 9 set. 2017.

FLUSSER, Vilém. Filosofia da caixa preta: ensaios para uma futura filosofia da fotografia. Rio de Janeiro: Relume Dumará, 2002.

FLUSSER, Vilém. 0 universo das imagens técnicas: elogio da superficialidade. São Paulo: Annablume, 2008.

FLUSSER, Vilém. A escrita: há futuro para a escrita? São Paulo: Annablume, 2010.

FRANK, Robert. Les américains. Paris: Robert Delpire, 1958.

FRANK, Robert. The Americans. Nova York: Grove Press, 1959.

GREENOUGH, Sarah. Digging Deep. In: STEIDL, Gerhard (org.). Robert Frank, books and films, 1947-2017. Munique: Steidl, 2017. p. 30.

KEROUAC, Jack. Introdução. In: FRANK, Robert. Os americanos. São Paulo: IMS, 2017. p. 7 12.

PARR, Martin; BADGER, Gerry. The photobook: a history. Londres: Phaidon, 2004. 
PARR, Martin; BADGER, Gerry. The photobook: a history. Londres: Phaidon, 2006. v. 2.

STEIDL, Gerhard. Robert Frank. The Americans. [S. l.]: Steidl, 2019.

STEIDL, Gerhard. The Americans por Gerhard Steidl | IMS Paulista. [Entrevista cedida a] Laura Liuzzi. [S. l.: s. n.], 10 set. 2017a. 1 vídeo (ca. 3 min).

STEIDL, Gerhard. The Epic Poet. In: STEIDL, Gerhard (org.). Robert Frank, Books and

Films, 1947-2017. Munique: Steidl, 2017b. p. 1.

The photobook in the technoimagetic environment: thoughts on the critical dimension of photography based on The Americans, by Robert Frank

\begin{abstract}
Considering the recent boom of photobooks in the editorial field, this paper aims to discuss their relevance to photography's circulation, especially when we live under a technoimagetic ambience dominated by the digital image and the screens. In order to do that, we analyse the editorial trajectory of The Americans, a photobook by Robert Frank, since its first edition (1958) until its most recent one (2008). As Frank's work maintains itself as an important reference for the photographic field, we suggest that photobooks play a decisive role not only in terms of circulation and propagation of ideas, but also in expanding the critical potential of photography.
\end{abstract}

\title{
Keywords
}

Photography. Robert Frank. Photobook. Technoimage.

\section{Autor correspondente}

Wagner Souza e Silva

wasosi@usp.br

\section{Como citar}

SILVA, Wagner Souza e; MAZZILLI, Bruna Sanjar. O fotolivro no ambiente tecnoimagético: considerações sobre a dimensão crítica da fotografia a partir de The Americans, de Robert Frank. Intexto, Porto Alegre, n. 52, e-94350, jan./dez. 2021. DOI: http://dx.doi.org/10.19132/1807-8583202152.94350 
Recebido em 08/07/2019

Aceito em 14/04/2020

(c) $(1)(9)$ 